\title{
Embedded System based Monitoring and Controlling of Parameters in Die Casting Industry
}

\author{
S.Thulasiram ${ }^{1}$, Dr. N.Suthanthira Vanitha ${ }^{2}$, M.Rajendiran ${ }^{3}$ and N.Kavitha ${ }^{4}$ \\ M.E Student, ${ }^{1}$ Department of Electrical and Electronics engineering, Knowledge \\ Institute of Technology, Salem, India. \\ ${ }^{2}$ Professor \& Head, Knowledge Institute of Technology, Salem, India. \\ ${ }^{3,4}$ Assistant Professor, Knowledge Institute of Technology, Salem, India.
}

\begin{abstract}
Die casting is the process for manufacturing the metal parts with desired shape for various industrial applications. Casting Process depends on many parameters variation such as die temperature, moisture level and viscosity of liquid level. At present days all the process parameters in die casting industry are measured manually. Manual measurement leads to error in measurement also time consuming. To overcome this issue non-contact type temperature measurement device is used for die temperature measurement but moisture and viscosity of the die is measured manually. Because die temperature is very sensitive one in die casting process. The proposed system is partially automated with PIC microcontroller and monitoring of the process is done through LabVIEW software.
\end{abstract}

Keywords: PIC microcontroller, IR temperature sensor, humidity sensor, viscosity sensor, LabVIEW software.

\section{Introduction}

The die casting industry is an efficient and economical process offering a wide range of shapes than any other manufacturing unit. During manufacturing a metal part the shapes of the metals depends upon the die temperature and liquid level. In this paper for monitoring the die casting parameters like die temperature, moisture level and viscous liquid level by using Embedded controller. In the conventional system the measurement of die parameters are achieved by manual process.

The proposed method provides an alternate solution by automation process. The die parameters like die temperature, viscous liquid level and moisture level are monitored by IR temperature sensor, viscosity sensor and humidity sensor through the PIC microcontroller .This controller controls the die casting process and efficient peripheral devices.

The sensor output is given to the processor which performs real time operation for an embedded controller, is programmed in such a way it any die parameters exceeds the threshold value, it alerts and control at the critical condition. Usually the die temperature should be maintained at constant temperature in between the range $180^{\circ} \mathrm{C}$ to $220^{\circ} \mathrm{C}$.

Based on the selection of temperature metal can be designed to the desired shape. During manufacturing a metal in die casting the metal should be clean and free from dust particles. To reduce the temperature of the die and lubricants the sprayer is fixed for the automatic cooling purpose. It is mixture of water and chemicals in which the ratio of combination process is $8: 3$.

Sometimes viscous level is varied if water level is high because the water has more solvent while comparing with that of chemicals. With the support of PIC microcontroller all these 
parameters are continuously monitored in the LCD and controlled automatically. The parameter variations can be graphically represented by using LabVIEW software.

\section{Literature Survey}

Guang Wei Liu a et al proposed a systematic experimental study which was conducted to examine the heat transfer characteristics from the hot die surface to the water spray involved in high pressure die casting processes. Temperature and heat flux measurements were made locally in the spray field using a heater made from die material H-13 steel and with a surface diameter of $10 \mathrm{~mm}$. The hydro dynamic parameter of the spray such as droplet diameters, droplet velocities, and volumetric spray flux were also measured at the position in the spray field identical to that of the test piece. Droplet size and velocity distribution were measured using a PDA system. A new empirical correlation was developed to relate the spray cooling heat flux to the spray hydro dynamic parameters such as liquid volumetric flux, droplet size, and droplet velocity in all heat transfer regimes. The agreement between experimental data and predicted results is satisfactorily good [1]

Nicola Gramegna - Engins of S.p.A.,Padova proposed the solidification and cooling dynamic of a metal alloy, in macroscopic terms, can be theoretically treated valuating the different contributions to the heat transfer from the liquid to the mould and the external environment Resistances to heat flux, coming from the inner side of the die-casting, are generally to be traced back to metal solidification, to the die-casting-mould interface and to the mould itself. In the die-casting case the heat absorbed from the external environment and the one removed through lubrication and blow operations cannot be ignored. The theoretic and scientific treatment of the heat balance allows us to analyses which are the prevalent factors for heat balance in case of the die-casting process. Real temperature monitoring and process simulation in working conditions are today the most used methods in order to understand the influence of every single factor. A sensitivity analysis, whether virtual or real, represents the best approach to define which is the contribution of every single factor within a well-defined production cycle or to a specific die-casting component [2].

M. Khalid Imran et al approached for high pressure die casting (HPDC) cooling time greatly affects the total cycle time. The thermal conductivity of the die material is the main governing factor in the cooling or solidification process. A higher thermal conductive die material allows faster extraction of heat from the casting, thus resulting in shorter cycle time and higher productivity. This paper presents a novel approach to replace a conventional steel tool die by a bimetallic tool die made of high strength copper coated with a protective layer of steel on the cavity surface for high pressure die casting of aluminum alloys. It is shown through finite element heat transfer analysis that the bimetallic die offers superior thermal performance compared with monolithic steel die. Results of thermal analysis using the ANSYS simulation software showed that bimetallic die reduces the cooling time to almost one third of the cooling time required for the conventional steel die[3].

Pankaj Chandna et al work analyzed different parameters of pressure die casting to minimize the casting defects. Pressure die casting is usually applied for casting of aluminium alloys. Good surface finish with required tolerances and dimensional accuracy can be achieved by optimization of controllable process parameters such as solidification time, molten temperature, filling time, injection pressure and plunger velocity. Moreover, by selection of optimum process parameters the pressure die casting defects such as porosity, insufficient spread of molten material, flash etc. are also minimized. Therefore, a pressure die casting component, carburetor housing of aluminium alloy $\left(\mathrm{Al}_{2} \mathrm{Si}_{2} \mathrm{O}_{5}\right)$ has been considered. The effects of selected process parameters on casting defects and subsequent setting of 
parameters with the levels have been accomplished by taguchi's parameter design approach. The experiments have been performed as per the combination of levels of different process parameters suggested by L18 orthogonal array. Analyses of variance have been performed for mean and signal-to-noise ratio to estimate the percent contribution of different process parameters. Confidence interval has also been estimated for $95 \%$ consistency level and three conformational experiments have been performed to validate the optimum level of different parameters. Overall $2.352 \%$ reduction in defects has been observed with the help of suggested optimum process parameters [4].

In Jacob O. Aweda et al proposed for permanent steel mold was designed, machined and evaluated by monitoring the temperature of squeeze cast aluminum and brass rods on a Vega hydraulic press. The operation was performed with and without pressure on the cast specimen at pouring temperature of $700^{\circ} \mathrm{C}$ and $980^{\circ} \mathrm{C}$ for aluminum and brass metals, respectively. The solidification rate (temperature with time) was monitored with a three-channel digital temperature monitor data logger while the tensile strengths of both samples were also determined. The results showed an increase in the solidification rate for both samples with increase in the applied pressure. The maximum solidification rate for aluminum was obtained at an applied pressure of $127 \mathrm{MPa}$ and $95 \mathrm{MPa}$ for brass. The tensile strength of both samples increased with increase in applied pressure. The maximum tensile strength of $34.38 \mathrm{MPa}$ was obtained for aluminum at applied pressure of $127 \mathrm{MPa}$ and $80.21 \mathrm{MPa}$ for brass at an applied pressure of $95 \mathrm{MPa}$. Above these values there was no significant increase in the tensile strength with increase in applied pressure. The results obtained were similar to that already established in the literatures which make the machined permanent steel mold suitable for squeeze casting of non-ferrous metals [5].

Dr. Dhrub Prasad et al approached for an optimization of process parameters of a cold chamber aluminium die casting operation is discussed. The quality problem encountered during the manufacturing of a die casted component was porosity and the various potential factors causing it are identified through a thorough cause-effect analysis. The Ishikawa diagram (cause and effect diagram) was constructed to identify the casting process parameters that may affect the porosity. An analysis of variance (ANOVA) is further conducted to find the factors having significant effects on porosity. The pressure of the plunger used in the die casting machine and the temperature of the liquid aluminium are identified as significant factors after the ANOVA test. Then a back propagation ANN is modelled and trained with the above two process parameters and porosity in order to predict or control the output by optimizing the input process parameters[6].

J.O. Aweda et al proposed for the effects of squeeze casting parameters, such as delay time and retention time of applied pressure and die pre-heating, on temperature distribution during casting of aluminium were investigated. During squeeze casting of molten aluminium increased in applied pressure and die pre-heating produced higher peak solidifying temperatures. Longer pressure retention time and shorter delay time gave higher peak solidifying temperature and product of excellent cast properties. The correlation between experimental measurements and computed numerical values of applied pressure, die heating temperature, delay time and retention time was very good[7].

Darina Matiskova et al proposed for the analysis of the temperature factors of die casting and the conditions of the service life of moulds. It also describes a mechanism of origin of internal structures and development of crystallization grains of aluminium castings depending on the degree of under cooling. The monitored factors are very important in terms of production efficiency and the quality of the casting, which is positively reflected in the most important economic indicators of the production. In die casting, the melted metal is pressed under high temperature into a mould cavity of significantly lower temperature. The mould is 
then exposed to thermal strain of individual surface layers. Increase in speed of cooling of the castings in the metal mould which, causes an increase of thermal gradients in the casting. Intensive heat exchange between the casting and the metal mould has a negative effect on fluidity, which increases the danger of incomplete replacement and the occurrence of cold joints [8]

\section{Existing Casting Process}

In existing method non-contact temperature measurement device were used for measuring the die temperature. All materials emits an amount of infrared radiation according to its surface temperature. The intensity of the infrared radiation changes according to the temperature of the object. Depending on the material and surface properties, the emitted radiation lies in a wavelength spectrum of approximately1 to $20 \mu \mathrm{m}$. The intensity of the infrared radiation ("heat radiation") is dependent on the material. For many substances this material-dependent constant is known as "emissivity value". Infrared thermometers are optical-electronic sensors. These sensors are able to detect radiation of heat".

Infrared thermometers are made up of a lens, a spectral filter, a sensor, and an electronic signal processing unit. The task of the spectral filter is to select the wavelength spectrum of interest. The sensor converts the infrared radiation into an electrical parameter. The connected electronics generate electrical signals for further analysis. As the intensity of the emitted infrared radiation is dependent on the material, the required emissivity can be selected on the sensor.

The biggest advantage of the infrared thermometer is its ability to measure in the absence of contact. Consequently, surface temperatures of moving or hard to reach objects can easily be measured. The desired spot size on the target will determine the maximum measurement distance and the necessary focus length of the optical module.

To avoid erroneous readings the target spot size must contain the entire field view of the sensor. Consequently, the sensor must be positioned so that the field view is the same as or smaller than the desired target size. It is used for measuring the die temperature in distance wise between different the parts and others two parameters like moisture level and viscous liquid level are monitored using manually.

\section{Proposed Casting Process}

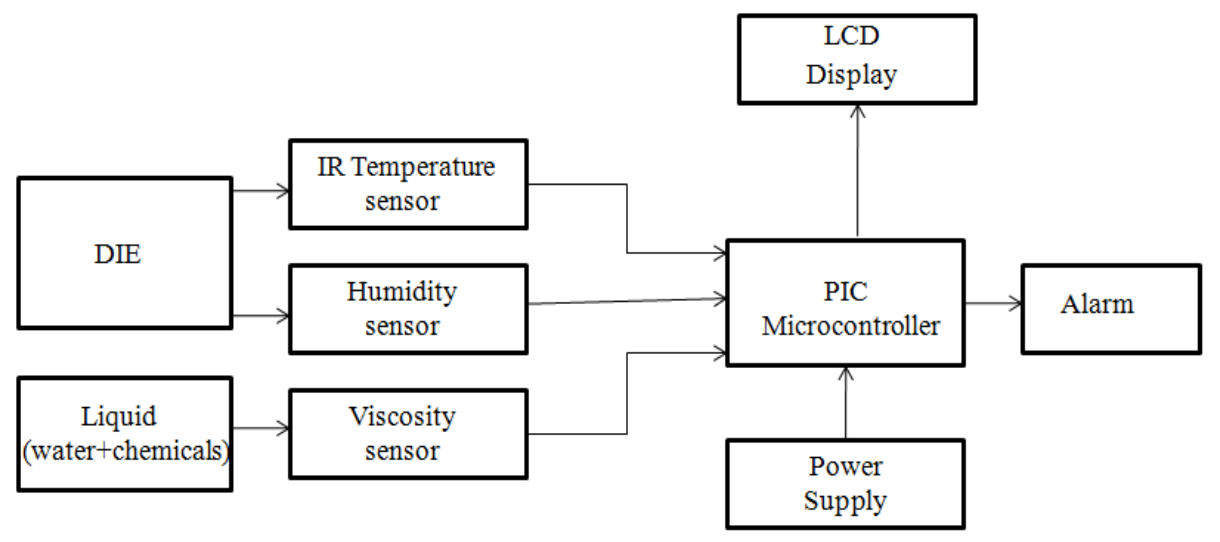

Figure 1. Block Diagram of Proposed System 
The die casting industry consists of various working units. This work focuses on die temperature, moisture level, and viscous liquid level. Usually the die temperature should be maintained at constant level ranges between $180^{\circ} \mathrm{C}$ to $220^{\circ} \mathrm{C}$. The IR temperature sensor for sense the temperature range from $-70^{\circ} \mathrm{C}$ to $+380^{\circ} \mathrm{C}$.After that sensed the die temperature analog signal is given to the controller.

Here the converts the analog signal to digital signal through inbuilt ADC in PIC microcontroller. If there is any increase in die temperature beyond threshold level to the controller controls automatically. Similarly to perform other two parameters are moisture level for identify in die using humidity sensor and viscous liquid level of spray using viscosity sensor. The LCD is used to display the parameter ranges and alarm is used to indicate the alert, when maintain level either increase or decrease. It can be graphically represented by using the LabVIEW

\section{Software Implementation}

LabVIEW means Laboratory Virtual Instrument Engineering Workbench. It is a platform and development environment for a visual programming language from National instruments. It is commonly used for data acquisition, instrument control and industrial automation on a variety of platforms. The front panel is built using controls and indicators. Controls are inputs - they allow a user to supply information to the VI. Indicators are outputs - they indicate to the VI. The back panel, which is a block diagram, contains the graphical source code.

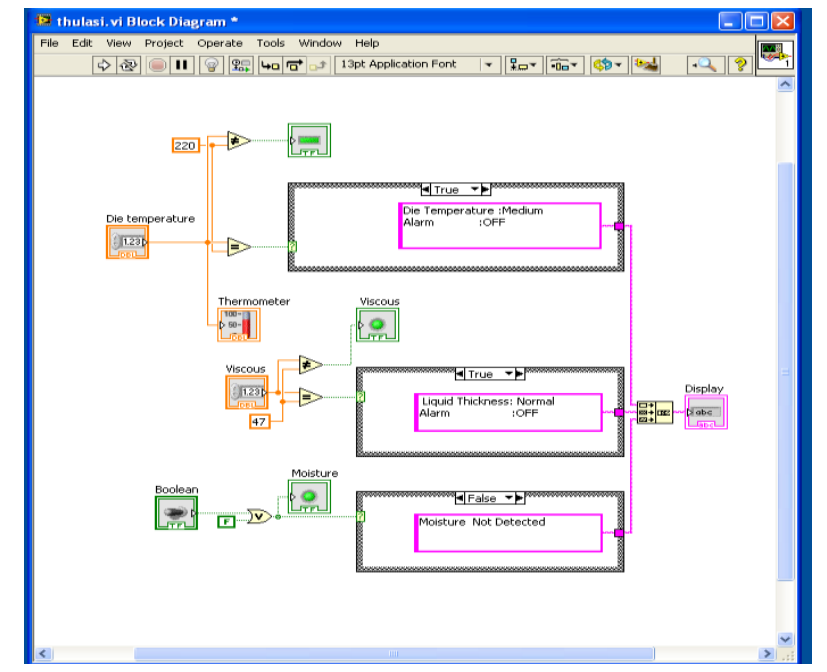

Figure 2. Block Diagram of Proposed System using LabVIEW 


\subsection{Flow Chart}

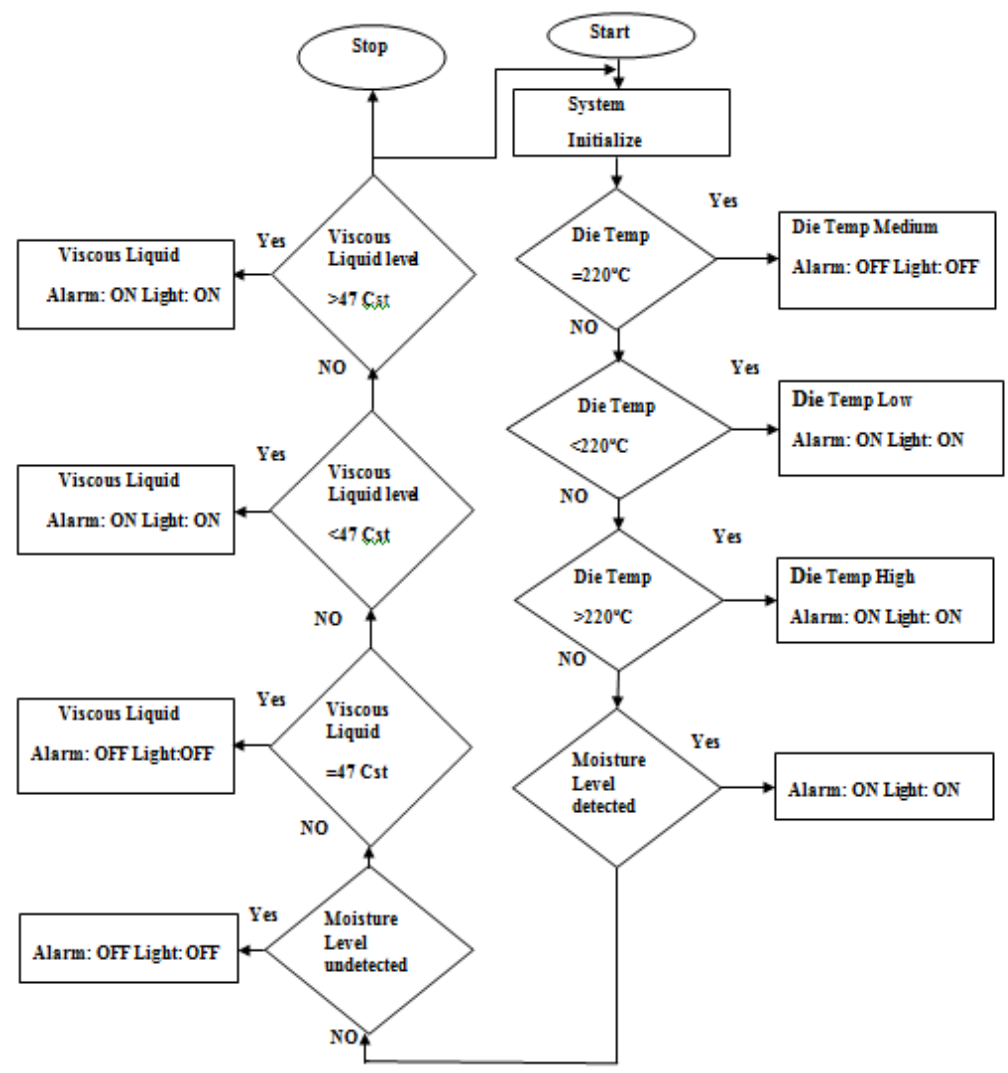

Figure 3. Flow Chart

\section{Results and Discussion}

\subsection{Process Parameters at Normal Condition}

When all the process parameters are at normal level,there is no indication output in LED and alarm.

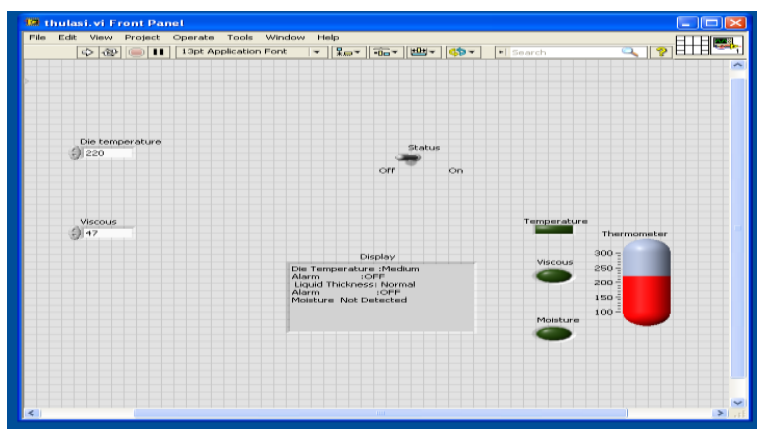

Figure 4. Process Parameters at Normal Condition 


\subsection{Process Parameters at Abnormal Condition}

\section{a. Die Temperature}

The die temperature should be maintain between $180^{\circ} \mathrm{C}$ up to $220^{\circ} \mathrm{C}$. In case any deviation in die temperature range, indicator will give the output.

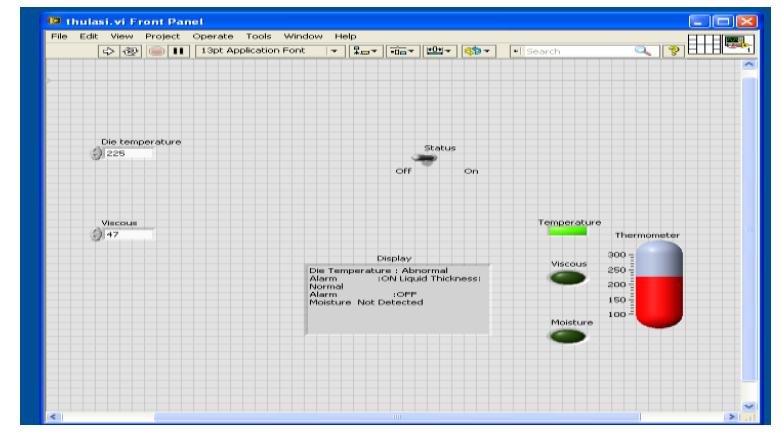

Figure 5. Die Temperature Output at Abnormal Condition

\section{b. Moisture Detection}

While manufacturing a metal product moisture content in die should be clean and additional with the humidity level, it is $0 \%$, when gradually raise above $0 \%$ it indicates the availability of moisture content.

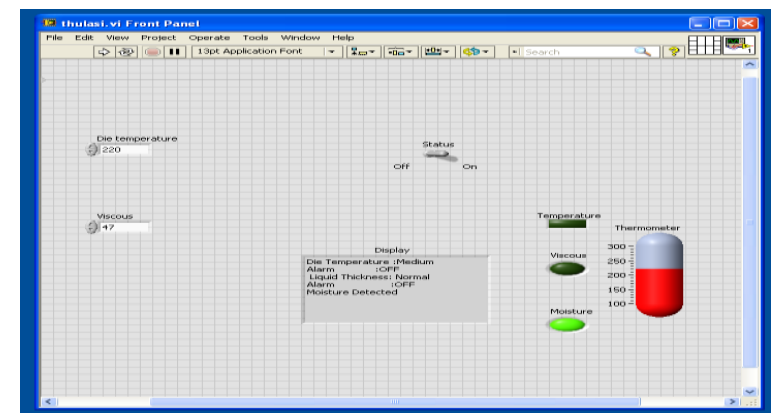

Figure 6. Moisture Output Detection

\section{c. Viscous of Liquid Level}

In spray which is mixture of water and chemicals therefore the viscous of liquid should be maintain at 47Cst.Here viscous liquid level is varied using front panel so LED is blinked and alarm becomes an $\mathrm{ON}$ condition. 


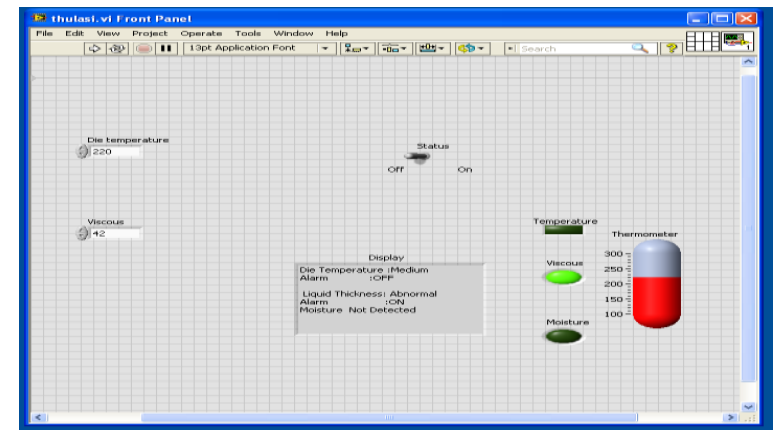

Figure 7. Viscous of Liquid Level Output at Abnormal Condition

\section{Conclusion}

The quality of Die casting process is mainly depends on die temperature, moisture level and viscous of liquid level. These process parameters are measurement and controlling is done manually. To reduce the error and time consumption in measurement automation is proposed. This proposed system produce die with good quality and reduces die damage then casting process entire automation in done with PIC microcontroller and LabVIEW also simulation results are produced for various parameter variation.

\section{References}

[1] B. R. Clayton, G. W. Liu, Y. S. Morsi, "Characterisation of the Spray Cooling Heat Transfer involve in a High Pressure Die Casting Process" Int.J.Therm.Sci., vol. 39, (2000), pp. 582-591.

[2] N. G. Engins, "Analysis of the Factors Contributing to the Heat Balance of an High Pressure Die-Casting Mould", (2006).

[3] S.H. Masood, M. Brandt, K. Imran, "Finite Element Heat Transfer Analysis of Copper Based Bimetallic Die for High Pressure Die Casting” IJAEA, vol. 2, no. 6, (2009), pp.1-5.

[4] A. K. Gupta, P. Chandna, S. Kumar "Optimization of Process Parameters of Pressure Die Casting using Taguchi Methodology”, 590 International Science Index, vol. 6, no. 8, (2012).

[5] J. O. Awedaa and M. Y. Kolawole "Performance Evaluation of Permanent Steel Mold for Temperature Monitoring During Squeeze Casting of Non- ferrous Metals", PJST, vol. 15, no. 1, (2014).

[6] D. Prasad, S. Ratna, "Application of Artificial Neural Network for Optimization of Cold Chamber Aluminum Die Casting", IJIRAE, vol. 5, (2014).

[7] M.B. Adeyemi and J.O. Aweda, "Effects of Squeeze Casting Parameters on Temperature Distribution During Casting Aluminum”, JAST, vol. 14, no. 1 - 2, (2009), pp. 67 - 73.

[8] D. Matiskova, L. Mura and S. Gaspar, "Thermal Factors of Die Casting and Their Impact on the Service Life of Moulds and the Quality of Castings", Acta Polytechnica Hungarica, vol. 10, no. 3, (2013).

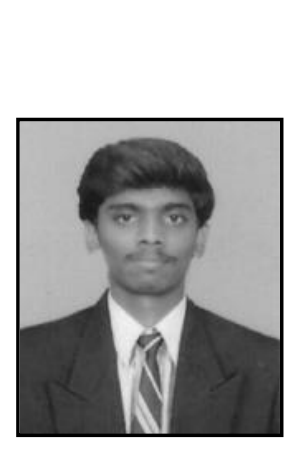

\section{Authors}

S.Thulasiram, he is pursuing, PG in the discipline of Embedded System Technologies at Knowledge Institute of Technology, Salem, under Anna University, Chennai, India. He received his UG degree in the discipline of Electronics and Communication Engineering from Sengunthar Engineering College, Tiruchengode under Anna University, Chennai, India. He has presented a number of technical papers and projects in Technical symposiums. He is the Executive member of Embedded Club at Knowledge Institute of Technology, Salem. He is doing minor research works on various fields like DSP, 


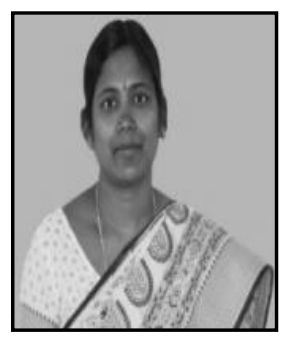

Embedded Systems, and Digital image processing. He got best project award for his project in UG.

N. Suthanthira Vanitha, she is currently working as a Professor and Head of the EEE Department at Knowledge Institute of Technology, Salem. She received the B.E. -Electrical and Electronics Engineering from K.S.R. college of Technology, Tiruchengode in 2000 from Madras University, M.E. - Applied Electronics in Kamaraj University and Ph.D., in Biomedical Instrumentation \& Embedded Systems in 2009 from Anna University, Chennai. She is life member of ISTE \& CSI. Her research interests lie in the area of Robotics, DSP, MEMS and Biomedical, Embedded Systems, Power Electronics and Renewable Energy systems, etc. She has published and presented number of technical papers in National and International Journals and Conferences. She has guided number of Projects for UG and PG students, currently guiding 10 Ph.D., scholars.

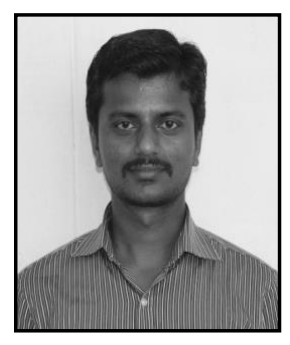

M. Rajendiran, he is currently working as an Assistant Professor in the Department of Electrical and Electronics Engineering at Knowledge Institute of Technology, Salem. He received his B.E. Electrical and Electronics Engineering and M.E.-Control \& instrumentation Degree from Kongu Engineering College under Anna University, Chennai. His research includes in control System, Robotics, and Renewable Energy Sources. He has published and presented number of technical papers in National and International conferences. He is guiding number of projects for UG and PG students.

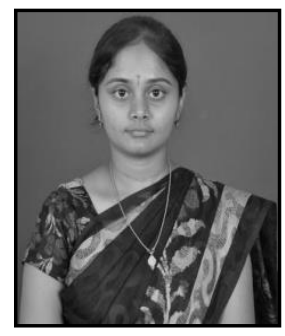

N.Kavitha is currently working as an Assistant Professor in the Department of Electrical and Electronics Engineering at Knowledge Institute of Technology, Salem. She received her B.E. - Electronics and communication Engineering Degree from K.S.Rangasamy College of Technology under Anna University, Chennai and M.E. - Control \&instrumentation from Kongu Engineering College under Anna University of Technology, Coimbatore. Her research includes in control System and Renewable Energy Sources. She has published and presented number of technical papers in National and International conferences. She is guiding number of projects for $\mathrm{UG}$ and $\mathrm{PG}$ students. 
International Journal of $u$ - and e- Service, Science and Technology Vol.8, No.5 (2015) 